\title{
Vibrational analysis of peptides, polypeptides, and proteins
}

\author{
XXX. Normal mode analyses of $\boldsymbol{\gamma}$-turns
}

\author{
JAGDEESH BANDEKAR and S. KRIMM
}

Biophysics Research Division, University of Michigan, Ann Arbor, MI, USA

\begin{abstract}
Received 8 November 1984, accepted for publication 14 February 1985
\end{abstract}
\begin{abstract}
The normal modes have been calculated for three kinds of low energy $\boldsymbol{\gamma}$-turn structures resulting from recent conformational energy calculations by Némethy. Frequencies have been computed for a $\gamma$-turn, a mirror-related $\gamma$-turn, and an inverse $\gamma$-turn of $\mathrm{CH}_{3}-\mathrm{CO}-(\mathrm{L}-\mathrm{Ala})_{n}-\mathrm{NH}-\mathrm{CH}_{3}$, with $\mathrm{n}=3$ and $\mathrm{n}=5$, and for certain ${ }^{14} \mathrm{C}$ and ${ }^{15} \mathrm{~N}$ derivatives of the $\mathrm{n}=3$ molecule. Correlations are evident between amide frequencies and $\gamma$-turn structures, and it is found that only amide $I$ modes of peptide groups in the turn are relatively insensitive to the lengths of attached chains.
\end{abstract}

Key words: $\mathrm{C}_{7}$ conformation; normal modes; $\gamma$-turns

Reverse turns, in which a polypeptide chain changes direction by $\sim 180^{\circ}$, give a protein its compact shape. Thus, an understanding of the structures and characteristics of such turns is of importance in understanding how proteins fold. Of the reverse turns, the $\beta$-turns have been clearly identified in various globular proteins (1), and we have carried out extensive vibrational spectroscopic studies on the different types of $\beta$-turns $(2-8)$. The result of these studies has been to provide useful correlations between vibrational spectrum and structure, and thus to give insight into the interpretation of protein spectra.

Encouraged by the success of these studies, we have now done normal mode analyses on another type of reverse turn, namely the $\gamma$ turn $(9,10)$. The $\gamma$-turn is formed by three amino acid residues, $i, i+1$, and $i+2$, and is characterized by two hydrogen bonds (see Fig. 1). That between the $\mathrm{CO}$ of residue $\mathrm{i}$ and the $\mathrm{NH}$ of residue $\mathrm{i}+2$ forms a $\mathrm{C}_{7}$ structure, since the ring of atoms enclosed by the peptide

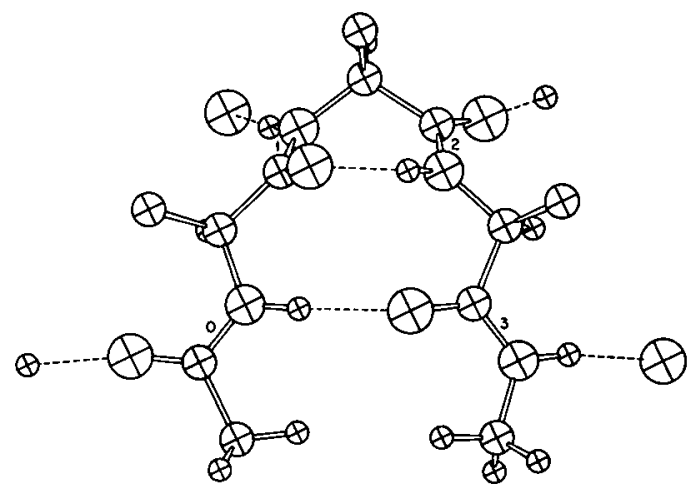

FIGURE 1

$\mathrm{CH}_{3}$-CO-(L-Ala) ${ }_{3}-\mathrm{NH}-\mathrm{CH}_{3}$ model of a $\gamma$-turn. $\mathrm{CH}_{3}$ groups of L-Ala residues are represented by point masses. External hydrogen bonds are formed by $\mathrm{NH}$ (to $\mathrm{O}$ atoms) and $\mathrm{CO}$ (to $\mathrm{H}$ atoms) groups. 
backbone and the hydrogen bond contains seven atoms. Although the $\mathrm{C}_{7}$ structure was discussed in the literature as early as 1943 (11), a specific $\gamma$-turn was proposed for the first time in 1972 by Némethy \& Printz (9). Since this early study, the $\gamma$-turn structure has been further refined using improved energy parameters (G. Némethy, private communication), and energetically stable conformations of three different types have been proposed: a) the $\gamma$ turn, $\gamma$, b) the mirror-related $\gamma$-turn, $\gamma_{M}$, and c) the inverse $\gamma$-turn, $\gamma_{I}$. In $\gamma$ and $\gamma_{M}$ there is a second hydrogen bond between the $\mathrm{NH}$ of residue $i$ and the $\mathrm{CO}$ of residue $\mathrm{i}+2$; in $\gamma_{\mathrm{I}}$ this bond is between the $\mathrm{CO}$ of residue $\mathrm{i}-1$ and the $\mathrm{NH}$ of residue $\mathrm{i}+3$.

The $\gamma$-turn does not occur as frequently as the $\beta$-turn, but it has been identified in some peptides and proteins. The cyclic tetrapeptide dihydrochlamydocin is known (12) to contain a $\gamma$-turn. Host-specific toxin from Helminthosporium carbium is claimed from n.m.r. studies to have a $\gamma$-turn (13). N.m.r. work from Urry's group (14) has shown that the repeat unit of the elastin polypentapeptide helix contains a $\gamma$-turn. And $\gamma$-turns have been found in at least 10 proteins (15). Finally, the $C_{7}^{a x}$ and $C_{7}^{e q}$ structures that have been discussed in the literature (16-19) are actually the normal and mirror-related $\gamma$-turns, respectively. $\left(\gamma_{I}\right.$ is also a $\mathrm{C}_{7}^{\mathrm{eq}}$ conformation). The present studies, therefore are expected to be useful in interpreting spectra of such structures.

We report here results of our normal mode analyses on model structures of the $\gamma, \gamma_{M}$, and $\gamma_{I}$ turns. The modes of the three-residue structure, modeled by $\mathrm{CH}_{3}-\mathrm{CO}-(\mathrm{L}-\mathrm{Ala})_{3}-\mathrm{NH}$ $\mathrm{CH}_{3}$ (see Fig. 1), are relevant to the spectra of small molecules having $\gamma$-turn structures. In addition, we have also calculated the normal modes of $\mathrm{CH}_{3}-\mathrm{CO}-(\mathrm{L}-\mathrm{Ala})_{5}-\mathrm{NH}-\mathrm{CH}_{3}$. This was done in order to examine the effects of nearest neighbor interactions, such as are likely to be found in proteins.

\section{NORMAL MODE CALCULATIONS}

The dihedral angles used for the various $\gamma$-turn conformations of $\mathrm{CH}_{3}-\mathrm{CO}-(\mathrm{L}-\mathrm{Ala})_{3}-\mathrm{NH}-\mathrm{CH}_{3}$ are given in Table 1. These values were kindly supplied to us by Dr. George Némethy, and are
TABLE 1

Dihedral angles for rturn structures of $\mathrm{CH}_{3}-\mathrm{CO}(\mathrm{L}-\mathrm{Ala})_{3} \cdot \mathrm{NH}-\mathrm{CH}_{3}$

\begin{tabular}{lrrr}
\hline & $\gamma$-Turn & $\gamma_{M}$-Turn & $\gamma_{\mathrm{I}}$-Turn \\
\hline$\omega_{0}{ }^{\mathrm{a}}$ & $180^{\mathrm{b}}$ & 180 & 180 \\
$\phi_{1}$ & -152 & -155 & 59 \\
$\psi_{1}$ & 90 & -53 & -177 \\
$\omega_{1}$ & -161 & 177 & 172 \\
$\phi_{2}$ & 58 & -81 & -77 \\
$\psi_{2}$ & -74 & 74 & 68 \\
$\omega_{2}$ & 178 & -179 & -176 \\
$\phi_{3}$ & -76 & -154 & -163 \\
$\psi_{3}$ & 149 & 158 & -55 \\
$\omega_{3}$ & -179 & -180 & 179 \\
\hline
\end{tabular}

${ }^{a}$ See Fig. 1 for designation of angles. ${ }^{b}$ In degrees.

the result of energy calculations using the latest form of ECEPP on terminally blocked (L-Ala) $)_{3}$ (G. Némethy, private communication). The relative energies of the above structures are (in $\mathrm{kcal} / \mathrm{mol}$ ) a) $\gamma: 8.32$, b) $\gamma_{\mathbf{M}}: 2.80$, c) $\gamma_{I}: 3.09$. The $\gamma$-turn, although of relatively high energy, forms a good chain reversal: the $\mathrm{H}_{\mathrm{i}+2} \ldots \mathrm{O}_{\mathrm{i}}$ and $\mathrm{H}_{\mathrm{i}} \ldots \mathrm{O}_{\mathrm{i}+2}$ distances are $1.86 \AA$ and $1.91 \AA$, respectively. The $\gamma_{M}$-turn is of relatively low energy but forms a very poor chain reversal: the $\mathrm{H}_{\mathrm{i}+2} \ldots \mathrm{O}_{\mathrm{i}}$ and $\mathrm{H}_{\mathrm{i}} \ldots \mathrm{O}_{\mathrm{i}+2}$ distances are $2.13 \AA$ and $6.06 \AA$, respectively. The $\gamma_{I^{-}}$-turn is characterized by both relatively low energy and good chain reversal: the $\mathrm{H}_{\mathrm{i}+2} \ldots \mathrm{O}_{\mathrm{i}}$ and $\mathrm{H}_{\mathrm{i}+3} \ldots \mathrm{O}_{\mathrm{i}-1}$ distances are $2.03 \AA$ and $1.92 \AA$, respectively.

The dihedral angles for the $\mathrm{CH}_{3}-\mathrm{CO}$-(LAla) $)_{5}-\mathrm{NH}-\mathrm{CH}_{3}$ structure (see Fig. 2) were the same in the turn region as for the smaller structure, the additional residues being taken to correspond to those of the antiparallel-chain pleated sheet, viz. $(\phi, \psi, \omega)_{0}=(\phi, \psi, \omega)_{4}=$ $-139^{\circ}, 133^{\circ}, 180^{\circ}$ (again $\omega_{\overline{1}}=180^{\circ}$ ). Although such a conformation is not necessarily present in all $\boldsymbol{\gamma}$-turns, and the frequencies will vary somewhat with these angles (see below), the $\phi, \psi$ values in many $\gamma$-turns in proteins are close to the $\beta$-sheet values (15). For both structures, in order to use our force fields, we used the bond lengths and bond angles of $\beta$-poly ( $L$ alanine) (20), while retaining the above dihedral angles. (This led to essentially identical $\mathrm{H}_{\mathrm{i}+2}$ $\ldots \mathrm{O}_{\mathrm{i}}$ distances, viz. $1.86,2.14$, and $2.04 \AA$, 


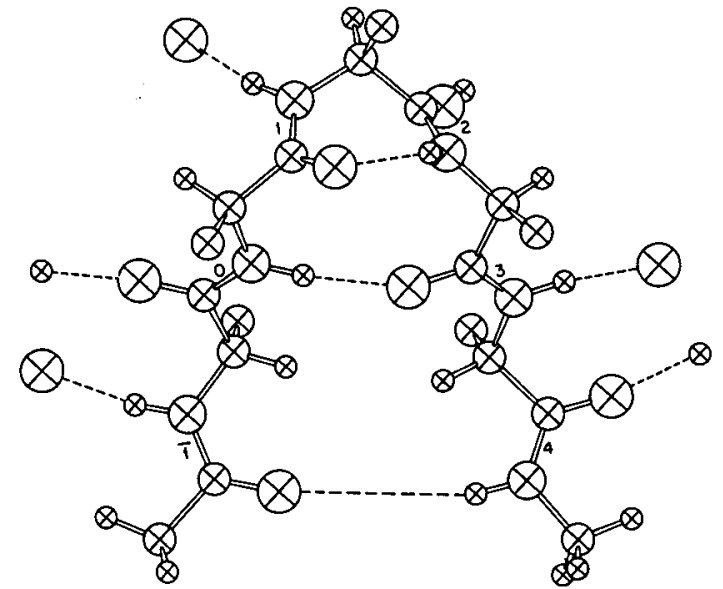

FIGURE 2

$\mathrm{CH}_{3}-\mathrm{CO}$-(L-Ala) $)_{5}-\mathrm{NH}-\mathrm{CH}_{3}$ model of $\gamma$-turn. $\mathrm{CH}_{3}$ groups of L-Ala residues are represented by point masses. Ex ternal hydrogen bonds are formed by $\mathrm{NH}$ (to $\mathrm{O}$ atoms) and $\mathrm{CO}$ (to $\mathrm{H}$ atoms) groups.

and slightly different $\mathrm{H}_{\mathbf{i}} \ldots \mathrm{O}_{\mathrm{i}+2}$ distances, viz. $1.99,6.24$, and $2.03 \AA$, for $\gamma, \gamma_{M}$, and $\gamma_{I}$, respectively, which is not expected to have a significant effect on the frequencies.)

It should be noted that the dihedral angles for the $\gamma$-turns given here are very different from those originally proposed (9). This is partly because of the improved potential functions used in the recent calculations (G. Némethy, personal communication), but is more a result of the early assumption (9) that the $\mathrm{i}+1$ residue is in the $C_{7}^{\mathrm{ax}}(\gamma)$ conformation. It was thought that this conformational region was only of moderately high energy for L-Ala, but subsequent studies on $\mathrm{CH}_{3}$-CO-L-Ala-NH$\mathrm{CH}_{3}(21,22)$ have shown that it is in fact of very high energy compared to the $\mathrm{C}_{7}^{\mathrm{eq}}\left(\gamma_{\mathrm{M}}\right)$ conformation. As indicated above, $\gamma_{M}$ is more stable than $\gamma$ by $5.52 \mathrm{kcal} / \mathrm{mol}$ in the (L-Ala) $)_{3}$ structure, thus indicating that, in the absence of other factors, it is a more likely conformation in small peptides and possibly proteins. We also note that the dihedral angles for $\gamma_{1}$ differ considerably from those originally reported for thermolysin and in the later refined structure deposited in the Protein Data Bank (23). This is undoubtedly a result of the influence of environmental interactions in the protein (G. Némethy, personal communication).
In the calculations, the side-chain Ala $\mathrm{CH}_{3}$ groups were replaced by point masses at the $C^{\beta}$ atom, the force field being a $\beta$ force field appropriate to this approximation (24) (the terminal $\mathrm{CH}_{3}$ groups were treated completely, using the detailed force field (20)). The force constants for the internal hydrogen bonds were assumed, as previously (2-4), to be $0.15 \mathrm{mdyn} /$ $\AA$ at $\mathrm{r}(\mathrm{H} \ldots \mathrm{O})=1.80 \AA$, decreasing linearly to zero at $5 \AA$. The external hydrogen bonds were all taken as equivalent, and the same as those for the $\beta$-turns $(2-4)$. Transition dipole coupling was incorporated for amide I and amide II modes $(25,26)$, using $\Delta \mu_{\text {eff }}=0.450 \mathrm{D}$ for amide I and 0.279D for amide II.

\section{RESULTS AND DISCUSSIONS}

\section{$\mathrm{CH}_{3}-\mathrm{CO}-(\mathrm{L}-\mathrm{Ala})_{3}-\mathrm{NH}-\mathrm{CH}_{3}$}

We present in Table 2 the calculated frequencies of the main amide modes for three $\gamma$-turn conformations of the (L-Ala) $)_{3}$ molecule. The main contribution to the potential energy distribution (PED) is given for each frequency, $\mathrm{CO}$ stretch for amide $\mathrm{I}, \mathrm{NH}$ in-plane bend for amide II and amide III, and NH out-of-plane bend for amide $V$. The peptide groups have been numbered such that group $i$ comprises $\mathrm{CO}_{\mathrm{i}}$ and $\mathrm{NH}_{\mathrm{i}+1}$.

Some of the amide I modes are significantly different for the three $\gamma$-turn structures, although it would be difficult to distinguish these conformations based on frequency ranges alone. It might be expected that the amide I mode associated with group 1, amide I(1), would be most sensitive to conformation, since the $\mathrm{CO}$ of peptide group 1 is directly involved in the hydrogen bond at the turn. Indeed, this mode shifts from $1670 \mathrm{~cm}^{-1}$ in $\gamma$ to $1656 \mathrm{~cm}^{-1}$ in $\gamma_{M}$ to $1660 \mathrm{~cm}^{-1}$ in $\gamma_{\mathrm{I}}$. The frequency of amide $I(2)$ is also sensitive to conformation, being predicted at $1656 \mathrm{~cm}^{-1}$ in $\gamma, 1668 \mathrm{~cm}^{-1}$ in $\gamma_{M}$, and $1667 \mathrm{~cm}^{-1}$ in $\gamma_{1}$. The latter result and, in part, the predictions for amide I(1) strongly suggest that the main conformational sensitivity is to whether the turn conformation is $C_{7}^{a x}(\gamma)$ or $C_{7}^{e q}\left(\gamma_{M}\right.$ and $\left.\gamma_{I}\right)$. The frequency of amide $I(0)$ seems (perhaps unexpectedly) to support this observation: it is predicted at $1684 \mathrm{~cm}^{-1}$ for $\gamma$ and at $1675 \mathrm{~cm}^{-1}$ for both $\gamma_{M}$ and $\gamma_{\mathrm{I}}$. 
TABLE 2

Calculated amide frequencies (in $\left.\mathrm{cm}^{-1}\right)$ of $\mathrm{CH}_{3} \cdot \mathrm{CO} \cdot(\mathrm{L}-\mathrm{Ala})_{3} \cdot \mathrm{NH} \cdot \mathrm{CH}_{3}$ in $\gamma$-turn conformations

\begin{tabular}{|c|c|c|c|c|c|c|c|c|c|}
\hline \multirow{3}{*}{$\begin{array}{c}\text { Mode } \\
\text { Amide I }^{\mathrm{b}}\end{array}$} & \multicolumn{3}{|c|}{$\boldsymbol{\gamma}$} & \multicolumn{3}{|c|}{$\gamma_{\mathbf{M}}$} & \multicolumn{3}{|c|}{$\gamma_{\mathrm{I}}$} \\
\hline & \multirow{2}{*}{$\frac{\nu}{1684}$} & \multicolumn{2}{|c|}{ PED $^{a}$} & \multirow{2}{*}{$\frac{\nu}{1675}$} & \multicolumn{2}{|c|}{ PED $^{a}$} & \multirow{2}{*}{$\frac{\nu}{1675}$} & \multicolumn{2}{|c|}{ PED $^{\mathrm{a}}$} \\
\hline & & $0(42)$ & $3(35)$ & & $0(45)$ & $3(31)$ & & $0(69)$ & $3(9)$ \\
\hline & 1670 & $1(74)$ & & 1668 & $2(73)$ & & 1667 & $2(68)$ & $1(9)$ \\
\hline & 1655 & $2(81)$ & & 1656 & $1(79)$ & & 1660 & $1(69)$ & $2(8)$ \\
\hline & 1653 & $3(39)$ & $0(38)$ & 1654 & $3(42)$ & $0(31)$ & 1649 & $3(72)$ & $0(9)$ \\
\hline \multirow[t]{4}{*}{ Amide II ${ }^{\mathbf{c}}$} & 1552 & $0(47)$ & & 1551 & $2(27)$ & $1(15) 0(9)$ & 1546 & $1(26)$ & $2(24)$ \\
\hline & 1529 & $1(36)$ & $3(8)$ & 1540 & $0(32)$ & $2(13)$ & 1540 & $1(25)$ & $2(24)$ \\
\hline & 1526 & $3(21)$ & $1(11)$ & 1527 & $3(30)$ & & 1512 & $3(30)$ & \\
\hline & 1509 & $2(47)$ & & 1518 & $1(40)$ & & 1503 & $0(31)$ & \\
\hline \multirow[t]{9}{*}{ Amide III ${ }^{\mathbf{d}}$} & 1390 & $0(12)$ & $1(6)$ & 1387 & $0(13)$ & & 1375 & $1(13)$ & \\
\hline & 1367 & $1(7)$ & & 1352 & $2(10)$ & & 1371 & $2(7)$ & \\
\hline & 1336 & $1(11)$ & & $1331^{*}$ & $1(7)$ & & 1351 & $3(5)$ & \\
\hline & 1327 & $3(9)$ & & $1310^{*}$ & $2(12)$ & $3(7) \quad 1(6)$ & 1346 & $0(26)$ & \\
\hline & $1297 *$ & $3(14)$ & $2(13)$ & $1261^{*}$ & $0(7)$ & & 1323 & $1(7)$ & \\
\hline & 1282 & $1(9)$ & & $1254^{*}$ & $3(21)$ & & $1308^{*}$ & $2(8)$ & $1(6)$ \\
\hline & $1242 *$ & $0(19)$ & & $1248^{*}$ & $0(6)$ & $1(6)$ & 1268 & $3(12)$ & $1(5)$ \\
\hline & $1225 *$ & $3(13)$ & $2(9)$ & & & & 1243* & $3(23)$ & $2(6)$ \\
\hline & & & & & & & $1232 *$ & $0(21)$ & \\
\hline \multirow[t]{9}{*}{ Amide $\mathrm{V}^{\mathbf{e}}$} & 709 & $3(7)$ & & 729 & $2(17)$ & & 718 & $1(16)$ & \\
\hline & 706 & $3(27)$ & & 719 & $1(14)$ & & 712 & $2(18)$ & $3(7)$ \\
\hline & 676 & $1(20)$ & & 707 & $3(34)$ & & 706 & $3(25)$ & \\
\hline & 655 & $1(12)$ & $2(6)$ & 677 & $2(12)$ & & 698 & $0(27)$ & $1(5)$ \\
\hline & 608 & $2(18)$ & & 643 & $1(12)$ & & [644] & {$[2(6)]$} & \\
\hline & 602 & $2(5)$ & & 570 & $0(40)$ & & & & \\
\hline & 548 & $0(32)$ & & 562 & $0(7)$ & & & & \\
\hline & 517 & $0(14)$ & & & & & & & \\
\hline & 493 & $0(12)$ & & & & & & & \\
\hline
\end{tabular}

a Potential energy distribution, with number of peptide group (see Fig. 1) and (in parentheses) the percentage of the contributing coordinate.

${ }^{b}$ Percentage of CO stretch.

${ }^{c}$ Percentage of $\mathrm{NH}$ in-plane bend. All modes also have a $\mathrm{CN}$ stretch contribution appropriate to the indicated peptide group.

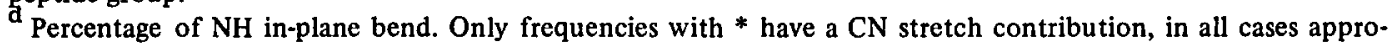
priate to the peptide group except the $1268 \mathrm{~cm}^{-1}$ band of $\gamma_{\mathrm{I}}$, which has a $\mathrm{CN}(2)$ stretch contribution.

Percentage of NH out-of-plane bend. All modes have a relevant $\mathrm{CN}$ torsion contribution, except $644 \mathrm{~cm}^{-1}$ of $\gamma_{\mathrm{I}}$ which has a $\mathrm{CN}(1)$ torsion contribution.

The relative sensitivity of the amide I(1) mode to conformation suggests that a more definitive structural assignment could be achieved by studying a suitable isotopically substituted molecule. We have therefore calculated the normal modes of $\mathrm{CH}_{3}-\mathrm{CO}-(\mathrm{L}-\mathrm{Ala})_{3}$ $\mathrm{NH}-\mathrm{CH}_{3}$ with ${ }^{14} \mathrm{C}$ substituted at the $\mathrm{CO}(1)$ position. The results are shown in Table 3 . As might be expected, the other amide I frequencies stay the same or decrease by several $\mathrm{cm}^{-1}$ (although amide $\mathrm{I}(3,0)$ of $\gamma_{M}$ is predicted to increase by $5 \mathrm{~cm}^{-1}$ ). The frequency of amide I(1) of course decreases, to $1588 \mathrm{~cm}^{-1}$ for $\gamma, 1570 \mathrm{~cm}^{-1}$ for $\gamma_{\mathrm{M}}$, and $1580 \mathrm{~cm}^{-1}$ for $\gamma_{\mathrm{I}}$. The location of the shifted band in the original sequence of amide I frequencies, plus the magnitude of the shift $(82,98$, and 80 $\mathrm{cm}^{-1}$ for $\gamma, \gamma_{M}$, and $\gamma_{I}$, respectively), could thus serve to identify the conformation with increased certainty. This serves to emphasize a 


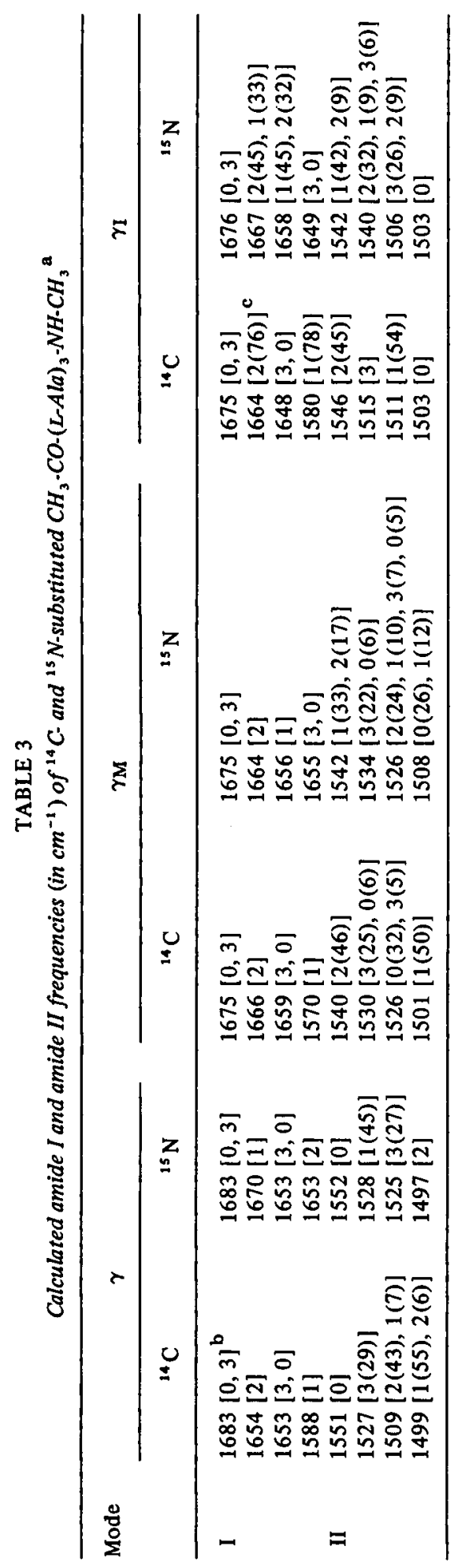

要

究要

동

急害总

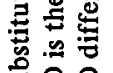

量是

语起

point not usually realized: spectra of backbone isotopically substituted molecules in conjunction with normal mode analysis provide a very powerful method for the determination of polypeptide chain conformation.

The calculated amide II modes have frequency distributions that are significantly different for the three conformations; this might be expected to permit a distinction between the structures (assuming the bands can be observed in the infrared, since Raman amide II modes are usually weak). The highest frequency, near $1550 \mathrm{~cm}^{-1}$, is about the same for all three structures, but a band near $1540 \mathrm{~cm}^{-1}$ is predicted only for $\gamma_{M}$ and $\gamma_{I}$. Similarly, only $\gamma$ and $\gamma_{M}$ have bands near $1527 \mathrm{~cm}^{-1}$, only $\gamma_{M}$ has a band near $1518 \mathrm{~cm}^{-1}$, and, whereas both $\gamma$ and $\gamma_{I}$ have bands near 1510 $\mathrm{cm}^{-1}$, only $\gamma_{\mathrm{I}}$ has a band as low as $1503 \mathrm{~cm}^{-1}$. The situation is more complex than for the amide I modes because, whereas the conformation-sensitive amide $I(1)$ and amide I(2) are relatively pure modes, the expected conformation-sensitive amide II(1) and amide II(2) modes are generally mixed, and differently for the three conformations.

As in the case of amide I, we have considered the sensitivity of amide II to isotopic substitution, both the ${ }^{14} \mathrm{C}$ substitution discussed above and ${ }^{15} \mathrm{~N}$ substitution at $\mathrm{NH}(2)$. The results of such normal mode calculations are shown in Table 3 . We note first that, as expected (since amide II involves CN stretch as well as NH in-plane bend), amide II(1) is significantly affected by the ${ }^{14} \mathrm{C}$ substitution, the predominant mode decreasing by 30,17 , and $\sim 32 \mathrm{~cm}^{-1}$ in $\gamma, \gamma_{M}$, and $\gamma_{I}$, respectively. The ${ }^{15} \mathrm{~N}$ substitution does not, of course, influence the amide I modes significantly, but it does have the expected effect on amide II(2). However, while it leads to an unambiguous drop of $12 \mathrm{~cm}^{-1}$ for $\gamma$, where the mode is relatively pure in $\mathrm{NH}$ in-plane bend, the situation is more complex for $\gamma_{M}$ and $\gamma_{I}$, where the already-mixed modes alter their state of mixing. Despite these complexities, such isotopic substitutions provide a new dimension of analysis of spectra in terms of conformation, and should help significantly in assigning structures.

A relatively large number of bands in the $1400-1200 \mathrm{~cm}^{-1}$ region contain $\mathrm{NH}$ in-plane 


\section{J. Bandekar and S. Krimm}

bend contributions at the $\geqslant 5 \%$ level, which we have found to be significant in determining $\mathrm{N}$ deuteration sensitivity (8). Although only three or four of these also have related $\mathrm{CN}$ stretch contributions, which are usually associated with "standard" amide III modes, we list all of these bands in Table 2. The patterns of both of these kinds of modes differ from one conformation to another, and whether this region can be used to distinguish between the structures depends on whether all or most of the modes appear in the Raman and infrared spectra. (Isotopic substitution does not appear to help much in this case, since the shifts are relatively small.) With this proviso, some points of difference should still be noted with respect to such $\mathrm{N}$ deuteration-sensitive modes: the lowest frequency is significantly different for the three conformations, viz. 1225,1248 , and $1232 \mathrm{~cm}^{-1}$ for $\gamma, \gamma_{M}$, and $\gamma_{I}$, respectively; while all structures have bands near $1305 \mathrm{~cm}^{-1}(1297,1310$, $1308 \mathrm{~cm}^{-1}$ ), the next lowest frequency is significantly different in the three conformations, viz. 1282,1261 , and $1268 \mathrm{~cm}^{-1}$ for $\gamma$, $\gamma_{M}$, and $\gamma_{I}$, respectively; while all structures have four bands in the region $\leqslant 1305 \mathrm{~cm}^{-1}$, the number above differ, viz. 4,3 , and 5 for $\gamma, \gamma_{M}$, and $\gamma_{I}$, respectively. Considering the extent of these differences, it seems probable that the amide III region could be used effectively to distinguish between these $\boldsymbol{\gamma}$-turn conformations.

The NH out-of-plane bend coordinate contributes to about $60 \%$ of the complex modes below $\sim 730 \mathrm{~cm}^{-1}$. For some of these, mostly in the $\sim 730-500 \mathrm{~cm}^{-1}$ region, this is combined with $\mathrm{CN}$ torsion in what is called amide $\mathrm{V}$, and which generally gives rise to moderately strong bands in the infrared spectrum. The calculated frequencies of such modes are given in Table 2 . The three $\gamma$-turn conformations show different amide $\mathrm{V}$ features, and again a differentiation based on this mode will depend on the appearance of these features in the spectra and their detection by $\mathrm{N}$ deuteration. Thus, the number of such modes differs between structures, viz. 9, 7, and 4 for $\gamma, \gamma_{M}$, and $\gamma_{I}$, respectively; the lowest frequency differs significantly, viz. 493, 562 , and $698 \mathrm{~cm}^{-1}$ for $\gamma, \gamma_{\mathrm{M}}$, and $\gamma_{\mathrm{I}}$, respectively; and there are important differences in distribution of modes, viz. 3,2 , and 0 in the $\$ 570$ $\mathrm{cm}^{-1}$ region, 4,2 , and 0 in the $570-680 \mathrm{~cm}^{-1}$ region, and 2,3 , and 4 in the $\gtrsim 700 \mathrm{~cm}^{-1}$ region, for $\gamma, \gamma_{M}$, and $\gamma_{I}$, respectively. It seems possible that the combination of the above characteristics in the amide $\mathrm{V}$ region could effectively differentiate between these $\gamma$-turn conformations.

\section{$\mathrm{CH}_{3}-\mathrm{CO}-(\mathrm{L}-\mathrm{Ala})_{5}-\mathrm{NH}-\mathrm{CH}_{3}$}

As noted above, we have also calculated the normal modes of $\gamma$-turn conformations of $\mathrm{CH}_{3}$ $\mathrm{CO}-(\mathrm{L}-\mathrm{Ala})_{5}-\mathrm{NH}-\mathrm{CH}_{3}$ in order to determine the effect of interactions of the added peptide groups on the frequencies of those groups characteristic of the turn. Such additional interactions would be present if the $\gamma$-turn occurred in a protein. The results of these calculations are given in Table 4 . The peptide groups are labeled (cf. Figs. 1 and 2) so that comparable groups in both molecules have the same number. The appropriate contributions to the PEDs are also given.

A comparison of Tables 2 and 4 shows that some modes are unchanged by the additional interactions whereas others are significantly affected. In the case of the amide I modes, the turn-sensitive frequencies of peptide groups 1 and 2 are, as might be expected, essentially unaffected in all three conformations. However, the frequencies of peptide groups 0 and 3 , perhaps as a result of their closer proximity to the added groups, are affected, decreasing for group 0 and increasing for group 3 . The situation for amide II is more complex. The conformation-sensitive frequencies of groups 1 and 2 are unaffected for $\gamma$ but change significantly for $\gamma_{M}$ and $\gamma_{I}$. For group 0 there is essentially no change for $\gamma$ and $\gamma_{I}$ but a large change for $\gamma_{M}$, while for group 3 the additional peptide groups cause large changes for all conformations. For amide III and amide $\mathrm{V}$ the changes display even greater complexity, and do not seem to furnish useful guidelines.

In order to see if the frequencies are influenced by structural changes beyond the first two hydrogen bonds, we calculated the modes of $\gamma$ for a structure in which $(\phi, \psi, \omega)_{0}=$ $(\phi, \psi, \omega)_{4}=-180^{\circ}, 100^{\circ}, 180^{\circ}$. This has the effect of keeping the first two hydrogen bond lengths the same, but increasing the $O(\overline{1}) \ldots$ $\mathrm{H}(4)$ distance from $3.69 \AA$ to $5.71 \AA$. The 
Normal mode analyses of $\gamma$-turns

TABLE 4

Calculated amide frequencies (in $\left.\mathrm{cm}^{-1}\right)$ of $\mathrm{CH}_{3} \cdot \mathrm{CO} \cdot(\mathrm{L} \cdot \mathrm{Ala})_{5} \cdot \mathrm{NH} \cdot \mathrm{CH}_{3}$ in $\gamma$-turn conformations

\begin{tabular}{|c|c|c|c|c|c|c|c|c|c|}
\hline \multirow[t]{2}{*}{ Mode } & \multicolumn{3}{|c|}{$\gamma$} & \multicolumn{3}{|c|}{$\gamma_{M}$} & \multicolumn{3}{|c|}{$\gamma_{\mathbf{I}}$} \\
\hline & $\nu$ & & PED $^{a}$ & $\nu$ & & $\operatorname{PED}^{\mathbf{a}}$ & $\nu$ & & PED $^{a}$ \\
\hline \multirow[t]{6}{*}{ Amide $\mathrm{I}^{\mathrm{b}}$} & 1675 & $0(47)$ & $3(23)$ & 1668 & $2(32)$ & $3(32) 4(11)$ & 1671 & $0(74)$ & \\
\hline & 1670 & $1(74)$ & & 1667 & $0(74)$ & & 1668 & $2(58)$ & $4(13)$ \\
\hline & 1666 & $4(56)$ & $3(19)$ & 1665 & $4(50)$ & $2(25)$ & 1667 & $4(62)$ & $2(12)$ \\
\hline & 1663 & $3(33)$ & $0(28) 4(14)$ & 1664 & $3(44)$ & $2(19) 4(14)$ & 1660 & $1(71)$ & $2(16)$ \\
\hline & 1655 & $2(81)$ & & 1655 & $1(80)$ & & 1655 & $3(79)$ & \\
\hline & 1650 & $I(82)$ & & 1649 & $\overline{1}(82)$ & & 1649 & $\overline{1}(82)$ & \\
\hline \multirow[t]{6}{*}{ Amide II $^{c}$} & 1554 & $0(45)$ & $3(6)$ & 1552 & $3(48)$ & & 1558 & $2(29)$ & $1(14) 3(9)$ \\
\hline & 1548 & $3(45)$ & $0(6)$ & 1547 & $\overline{1}(50)$ & & 1547 & $\overline{\mathrm{I}}(50)$ & \\
\hline & 1547 & $\mathrm{~T}(50)$ & & 1547 & $1(27)$ & $0(15) 2(10)$ & 1541 & $3(32)$ & $1(21)$ \\
\hline & 1527 & $1(47)$ & & 1544 & $2(36)$ & $1(11)$ & 1525 & $2(21)$ & $1(17) 3(13)$ \\
\hline & 1521 & $4(28)$ & & 1515 & $4(26)$ & & 1513 & $4(24)$ & \\
\hline & 1509 & $2(48)$ & & 1510 & $0(30)$ & $1(16)$ & 1506 & $0(38)$ & \\
\hline \multirow[t]{12}{*}{ Amide III ${ }^{d}$} & 1390 & $\overline{1}(7)$ & $0(5)$ & 1387 & $\overline{1}(10)$ & & 1384 & $\overline{1}(12)$ & \\
\hline & 1372 & $1(13)$ & & 1384 & $3(7)$ & & 1376 & $1(9)$ & \\
\hline & 1358 & $3(9)$ & & 1362 & $0(6)$ & & 1367 & $2(6)$ & \\
\hline & 1329 & $1(10)$ & $0(5)$ & 1341 & $2(11)$ & & 1328 & $0(21)$ & \\
\hline & 1298 & $2(8)$ & $4(8)$ & $1322 *$ & $1(7)$ & & 1323 & $2(5)$ & \\
\hline & 1288 & $1(7)$ & & 1317 & $0(5)$ & & $1308^{*}$ & $2(8)$ & $1(7)$ \\
\hline & 1266 & $0(12)$ & & 1305 & $2(8)$ & $4(5)$ & 1273 & $3(11)$ & $4(7)$ \\
\hline & 1250 & $4(18)$ & $2(8)$ & 1271 & $3(9)$ & $4(8) 0(5)$ & 1267 & $0(13)$ & $3(7)$ \\
\hline & $1238^{*}$ & $\overline{1}(19)$ & & 1268 & $0(14)$ & & 1255 & $1(6)$ & \\
\hline & $1232^{*}$ & $3(11)$ & $4(7) 2(5)$ & $1254^{*}$ & $1(9)$ & $2(7)$ & 1238 & $\overline{1}(16)$ & \\
\hline & & & & $1239 *$ & $\mathbf{1}(17)$ & & 1228 & $4(20)$ & \\
\hline & & & & 1237 & $4(19)$ & & & & \\
\hline \multirow[t]{13}{*}{ Amide $\mathrm{V}^{\mathbf{e}}$} & 704 & $\overline{1}(7)$ & $3(6)$ & 792 & $4(26)$ & & 710 & $1(12)$ & \\
\hline & 698 & $1(10)$ & $3(7)$ & 709 & $1(18)$ & & 707 & $\overline{1}(14)$ & \\
\hline & 685 & $3(12)$ & & 701 & $\overline{1}(18)$ & & 702 & $1(11)$ & $\overline{1}(7)$ \\
\hline & 674 & $1(17)$ & & 696 & $3(25)$ & & 692 & $3(20)$ & \\
\hline & 658 & $1(12)$ & $2(5)$ & 689 & $2(10)$ & & 679 & $0(17)$ & $2(11)$ \\
\hline & $637^{\dagger}$ & $\overline{1}(6)$ & & 674 & $0(5)$ & & 674 & $2(17)$ & \\
\hline & $627^{\dagger}$ & $\overline{1}(5)$ & & 659 & $2(19)$ & & 646 & $2(7)$ & \\
\hline & 610 & $2(9)$ & & 646 & $1(10)$ & & 638 & $3(10)$ & \\
\hline & 604 & $2(16)$ & & 640 & $0(10)$ & & $619^{\dagger}$ & $\overline{1}(10)$ & \\
\hline & 581 & $4(41)$ & & $625^{\dagger}$ & $\overline{1}(6)$ & & $607^{\dagger}$ & $\overline{1}(8)$ & \\
\hline & 561 & $0(21)$ & & 615 & $3(7)$ & $0(5)$ & $580^{\dagger}$ & $1(5)$ & \\
\hline & 481 & $0(21)$ & & 595 & $0(18)$ & & 557 & $4(38)$ & \\
\hline & 478 & $0(10)$ & & & & & & & \\
\hline
\end{tabular}

a Potential energy distribution, with number of peptide group (see Fig. 2) and (in parentheses) the percentage of the contributing coordinate.

${ }^{b}$ Percentage of CO stretch.

c Percentage of NH in-plane bend. All modes also have a $\mathrm{CN}$ stretch contribution appropriate to the indicated peptide group.

d Percentage of NH in-plane bend. Only frequencies with * have a $\mathrm{CN}$ stretch contribution.

Percentage of NH out-of-plane bend. All modes, except those with $\dagger$, have a relevant CN torsion contribution. 
effects of this change are as follows: the amide I frequencies remain the same for peptide groups 0 and 2 , and change by no more than $2 \mathrm{~cm}^{-1}$ for the others; all of the amide II frequencies change (one by as much as $13 \mathrm{~cm}^{-1}$ ), that for group 0 increasing from 1554 to 1563 $\mathrm{cm}^{-1}$ and that for group 2 decreasing from 1509 to $1501 \mathrm{~cm}^{-1}$; all of the amide III modes shift slightly (all except one by $4 \mathrm{~cm}^{-1}$ or less), that for group 0 remaining the same and that for group 2 decreasing by $1 \mathrm{~cm}^{-1}$; and the pattern of amide $\mathrm{V}$ frequencies changes significantly, including those of groups 0 and 2 . It appears that most of the amide modes of $\gamma$ turns are sensitive to the local environment.

As a result of these comparisons it can be said that the amide I modes of peptide groups 1 and 2 are relatively insensitive to the lengths of the attached chains, and therefore that deductions based on these amide I predictions have some measure of generality. (This may be useful in analyzing spectra of small molecules having $\mathrm{C}_{7}$ structures (17)). This is not true of other groups and other amide modes, and therefore it is preferable to use calculations that are most relevant to the structure being studied. This is evident from the results presented in the accompanying paper (27).

\section{CONCLUSIONS}

The results of our normal mode calculations (Tables 2 and 4) should provide guidelines for identifying $\gamma$-turns. Of course, it must be realized that the calculations are restricted in several aspects: we have assumed specific dihedral angles appropriate to energy-minimized $(\mathrm{L}-\mathrm{Ala})_{3}$ structures while dihedral angles in a particular molecule may deviate from these because of interaction effects; although we have allowed for a variation in the $\mathrm{f}(\mathrm{H}$. . . O) stretching force constant with hydrogen bond length, we have not taken into account changes in other force constants of the hydrogen bond (of which relatively little is known), which may have an effect particularly on the lower frequencies such as amide $\mathrm{V}$; we have assumed that force constants are the same for all peptide groups, which may not be true in a specific molecule, especially if residues such as proline are present $(27,28)$. A more general problem in identifying $\gamma$-turn conformations involves the overlapping of such frequencies with those for other kinds of structures, such as $\beta$-turns (3). This situation, of course, does not have a general solution, but the kind of isotopic substitution discussed above can provide answers in specific cases.

In spite of the above problems, these normal mode analyses should provide useful guidelines in analyzing the vibrational spectra of $\gamma$-turns.

\section{ACKNOWLEDGMENTS}

This research was supported by National Science Foundation grants PCM-8214064 and DMR-8303610. We are indebted to Dr. George Nemethy for providing the coordinates of the $\gamma$-turn structures.

\section{REFERENCES}

1. Chou, P.Y. \& Fasman, G.D. (1977) J. Mol. Biol. 115, 135-175

2. Bandekar, J. \& Krimm, S. (1979) Proc. Natl. Acad. Sci. US 76, 774-777

3. Krimm, S. \& Bandekar, J. (1980) Biopolymers 19, 1-29

4. Bandekar, J. \& Krimm, S. (1980) Biopolymers 19, 31-36

5. Bandekar, J. \& Krimm, S. (1979) in Peptides: Structure and Biological Function, Proceedings of the Sixth American Peptide Symposium (Gross, E. \& Meienhofer, J., eds.), pp. 241244, Pierce Chemical Co., Rockford, IL

6. Maxfield, F.R., Bandekar, J., Krimm, S., Evans, D.J., Leach, S.J., Némethy, G. \& Scheraga, H.A. (1981) Macromolecules 14, 997-1003

7. Bandekar, J., Evans, D.J., Krimm, S., Leach, S.J., Lee, S., McQuie, J.R., Minasian, E., Nemethy, G., Pottle, M.S., Scheraga, H.A., Stimson, E.R. \& Woody, R.W. (1982) Int. J. Peptide Protein Res. 19, 187-205

8. Naik, V.M. \& Krimm, S. (1984) Int. J. Peptide Protein Res. 23, 1-24

9. Nemethy, G. \& Printz, M.P. (1972) Macromolecules 5, 755-758

10. Smith, J.A. \& Pease, L.G. (1980) Crit. Rev. Biochem. 8, 315-399

11. Huggins, M.L. (1943) Chem. Rev. 32, 195-218

12. Flippen, J.L. \& Karle, I. (1976) Biopolymers 15, 1081-1092

13. Kawai, M., Rich, D.H. \& Watson, J.D. (1983) Biochem. Biophys. Res. Commun. 111, 398-403

14. Urry, D., Mitchell, L.W., Ohnishi, T. \& Long, M.M. (1975) J. Mol. Biol. 86, 101-117 
15. Baker, E.N. \& Hubbard, R.E. (1984) Progr. Biophys. Mol. Biol. 44, 97-179

16. Lipkind, G.M., Arkhipova, S.F. \& Popov, E.M. (1971) Mol. Biol. 4, 409-414

17. Neel, J. (1972) Pure Appl. Chem. 31, 201-225

18. Bystrov, V.F., Portnova, S.L., Tsetlin, V.I., Ivanov, V.T. \& Ovchinnikov, Y.A. (1969) Tetrahedron 25, 493-515

19. Pullman, B. \& Pullman, A. (1974) Advan. Protein Chem. 28, 347-526

20. Dwivedi, A.M. \& Krimm, S. (1982) Macromolecules 15, 186-193; (1983) 16,340

21. Zimmerman, S.S., Pottle, M.S., Némethy, G. \& Scheraga, H.A. (1977) Macromolecules 10, 1-9

22. Vasquez, M., Nemethy, G. \& Scheraga, H.A. (1983) Macromolecules 16, 1043-1049

23. Bernstein, F.C., Koetzle, T.F., Williams, G.J.B., Meyer, E.F., Brice, M.D., Rodgers, J.R., Kennard, O., Shimanouchi, T. \& Tasumi, M. (1977) J. Mol. Biol. 112, 535-542
24. Dwivedi, A.M. \& Krimm, S. (1984) J. Phys. Chem. 88, 620-627

25. Krimm, S. \& Abe, X. (1972) Proc. Natl. Acad. Sci. US 69, 2788-2792

26. Moore, W.H. \& Krimm, S. (1975) Proc. Natl. Acad. Sci. US 72, 4933-4955

27. Bandekar, J. \& Krimm, S. (1985) Int. J. Peptide Protein Res. 26, 158-165

28. Boussard, G., Marraud, M. \& Neel, J. (1974) J. Chim. Phys. 71, 1081-1091

Address:

Dr. S. Krimm

Biophysics Research Division

University of Michigan

Ann Arbor, MI 48109

USA 